\title{
Recent Developments in Electronic, Functional, and Biological Thin Films
}

\author{
ROGER NARAYAN ${ }^{1,2}$ \\ 1.-Joint Department of Biomedical Engineering, University of North Carolina, Campus \\ Box 7575, Chapel Hill, NC 27599, USA. 2.—e-mail: roger_narayan@msn.com
}

The use of surface modification by humans dates back several millennia. As noted by Myers, the art of Cro-Magnon man in 15,000 B.C. can be considered to be a decorative coating. ${ }^{1}$ Oddy noted that applying gold to surfaces has been performed for at least 5000 years. $^{2}$

Processing of thin films for applications other than gilding began in earnest in the nineteenth century. At the beginning of the nineteenth century, Luigi Brugnatelli used electroplating to deposit gold; by the middle of that century, deposition of a variety of metals had been demonstrated. ${ }^{3}$ Sir Robert Grove described a process that he termed "cathodic disintegration" in 1852; Sir John Thompson later renamed this process "sputtering." 4 As noted by Mattox, Michael Faraday described sputtering within a glow discharge tube for deposition of films in the mid-nineteenth century. ${ }^{5}$ At the turn of the last century, Thomas Edison used sputtering to deposit gold coatings on master wax cylinders, which were subsequently used to produce "Gold Moulded Records." ${ }^{6}$ The origin of chemical vapor deposition has been traced to early studies by von Guericke and Henry. ${ }^{7}$ It was used for development of light bulb materials in the 1880s and for purification of refractory metals in the $1940 \mathrm{~s}^{7,8}$ Over the past half century, rapid developments in thin film technology were associated with increases in complexity and reductions in size of electronic and optical devices. For example, Smith and Turner used evaporation by a ruby laser to create films of a variety of materials, including $\mathrm{As}_{2} \mathrm{~S}_{3}, \mathrm{Ge}, \mathrm{MoO}_{3}, \mathrm{PbTe}, \mathrm{Sb}_{2} \mathrm{~S}_{3}$, Se, Te, and ZnTe. ${ }^{9}$ Currently, pulsed laser deposition is commonly used for deposition of a variety of thin films, including multicomponent systems and biologically relevant materials, at low temperatures. ${ }^{10}$

At the beginning of the twenty-first century, significant thin film research activities involve the development of thin films for medical and energy applications. In this issue, Gupta et al. considered the protein adsorption and wettability of composite materials containing ultrahigh molecular weight polyethylene, hydroxyapatite, alumina, and carbon nanotubes; these materials have potential use in joint replacement prostheses. Palkowski et al. created a three-layered stainless steel/polypropylene copolymer/stainless steel sandwich sheet material with biomimetic properties. Skoog et al. deposited ultrananocrystalline diamond films on microporous silicon nitride membranes using microwave plasma chemical vapor deposition and evaluated the growth of human epidermal keratinocytes on these materials. Shet et al. prepared zinc oxide thin films using radio frequency sputtering in the presence of a gas ambient containing argon and nitrogen. They demonstrated that aligned nanoscale structures with enhanced photoelectrochemical response were prepared under an appropriate gas ambient. It is hoped that this special issue helps to generate discussions in industry, academia, and government regarding use of thin film technology for electronic, functional, and biological applications.

\section{REFERENCES}

1. R.R. Myers, J. Macromol. Sci. Chem. 15, 1133 (1981).

2. A. Oddy, Gold Bull. 14, 75 (1981).

3. A.P. Abbott, I. Dalrymple, F. Endres, and D.R. MacFarlane, Electrodeposition from ionic liquids. ed. F. Endres, D. MacFarlane, and A. Abbott (Hoboken, NJ: Wiley).

4. R. Powell and S.M. Rossnagel, PVD for Microelectronics: Sputter Desposition to Semiconductor Manufacturing (San Diego, CA: Academic Press, 1998) $1 \mathrm{pp}$.

5. D.M. Mattox, The Foundations of Vacuum Coating Technology (Norwich, NY: Noyes, 2003), $11 \mathrm{pp}$.

6. D.M. Mattox, The Foundations of Vacuum Coating Technology (Norwich, NY: Noyes, 2003), pp. 11-12.

7. D.M. Mattox, The Foundations of Vacuum Coating Technology (Norwich, NY: Noyes Publishing, 2003), 27 pp.

8. Y. Xu and X.T. Yan, Chemical Vapor Deposition: An Integrated Engineering Design for Advanced Materials (London, U.K.: Springer, 2010).

9. H.M. Smith and A.F. Turner, Appl. Opt. 4, 147 (1965).

10. R. Narayan and P. Goering, MRS Bull. 36, 973 (2011). 